\title{
Endoscopic ultrasound-guided management of bleeding periampullary tumor
}

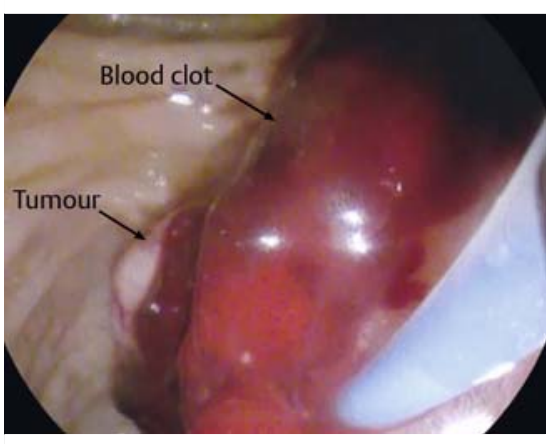

- Fig. 1 Image from side-viewing endoscopy showing a blood clot covering the tumor. The clot was removed and epinephrine was injected to achieve hemostasis.

A 72-year-old man presented with melena and a drop in hemoglobin from $10 \mathrm{~g} / \mathrm{dL}$ to $5 \mathrm{~g} / \mathrm{dL}$. He required three units of blood for hemodynamic stabilization. He had undergone endoscopic retrograde cholangiopancreatography (ERCP) with biliary plastic stenting 4 days previously for a periampullary tumor. On side-viewing endoscopy, a blood clot covering the tumor was found and removed, with $20 \mathrm{~mL}$ of 1:10000 epinephrine injected to achieve hemostasis ( $>$ Fig. 1 ).

A repeat side-viewing endoscopy on the second day showed no active bleeding.
However, he bled massively after 48 hours and was sent for CT angiography which revealed ampullary mass without any demonstrable source of bleeding. An endoscopic ultrasound (EUS) examination demonstrated the course of the blood vessels proceeding towards the tumor ( Fig. 2 a; $>$ Video 1). An EUS-guided intervention was planned to control the periampullary bleeding, keeping in mind the normal blood supply to the ampulla. A 25-gauge EUS needle was used to puncture one of the branches of the gastroduodenal artery (GDA) closer to the second part of the duodenum and $1 \mathrm{~mL}$ of $99.9 \%$ absolute alcohol was injected ( Fig. 2 b). A further $1 \mathrm{~mL}$ of alcohol was injected around another branch proceeding towards the tumor in a periarterial location ( $\mathbf{F i g} \cdot \mathbf{2 c}$ ). Following this EUS-guided alcohol injection, repeat side-viewing endoscopy showed no active bleeding.

Unfortunately, the patient did rebleed again on day 6 , with active ooze around the ampullary growth. Emergency Whipple's procedure was not considered given the patient's unwillingness to undergo such surgery at that time. Therefore, EUS-guided coiling of the GDA was planned as a salvage treatment. The transducer was placed in the antrum par- allel to the GDA so that its diameter could be measured to select the size of microcoil required ( $\vee$ Fig. 3 a). The GDA was punctured with a 22-gauge needle under EUS guidance and two microcoils of $4 \mathrm{~mm}$ in size were placed ( $\mathbf{F i g} \mathbf{3} \mathbf{b}$; - Video 1). Repeat side-viewing endoscopy showed no active bleeding. The patient later underwent a Whipple's procedure, which showed well-differentiated ampullary adenocarcinoma.

Endoscopy_UCTN_Code_TTT_1AS_2AD

Competing interests

None

The authors

Malay Sharma ${ }^{1}$, Piyush Somani ${ }^{1}$, Tagore Sunkara ${ }^{2}$, Ritesh Prajapati ${ }^{1}$

1 Department of Gastroenterology, Jaswant Rai Speciality Hospital, Saket, Meerut, Uttar Pradesh, India

2 Department of Gastroenterology and Hepatology, The Brooklyn Hospital Center, Clinical Affiliate of the Mount Sinai Hospital, Brooklyn, New York, USA
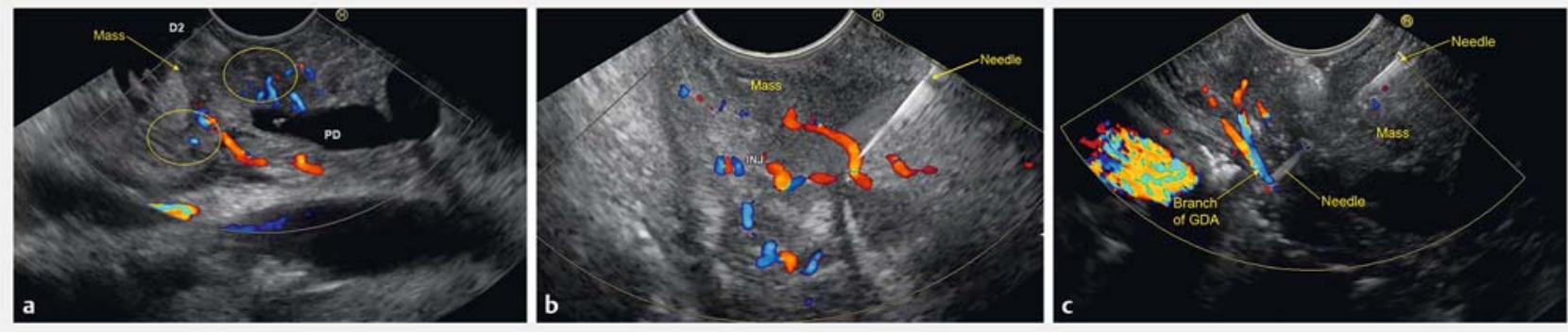

Fig. 2 Linear endoscopic ultrasound (EUS) images from the descending duodenum showing: a the course of the blood vessels proceeding towards the periampullary tumor; $\mathbf{b}$ a 25 -gauge EUS needle being used to puncture one of the branches of the gastroduodenal artery (GDA) closer to the second part of the duodenum, through which $1 \mathrm{~mL}$ of $99.9 \%$ absolute alcohol was injected; c injection of a further $1 \mathrm{~mL}$ of alcohol around a branch of the GDA proceeding towards the tumor in a periarterial location. 

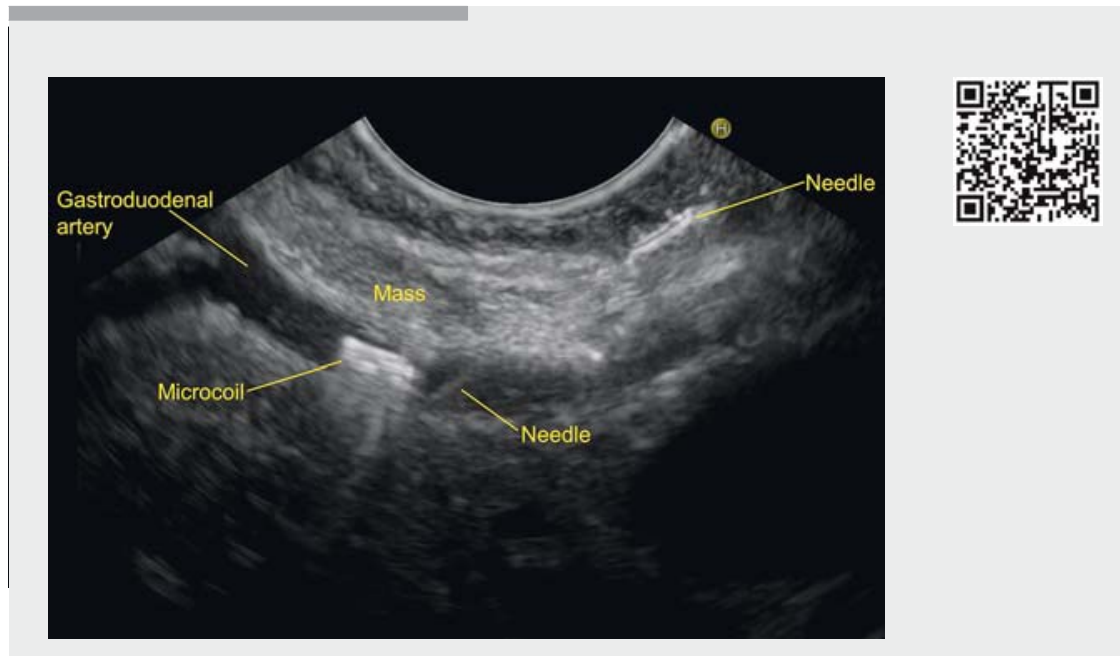

Video 1 The video shows endoscopic ultrasound-guided management of bleeding from a periampullary tumor, including injection of alcohol in and around the arteries supplying the tumor and subsequent coiling of the gastroduodenal artery.
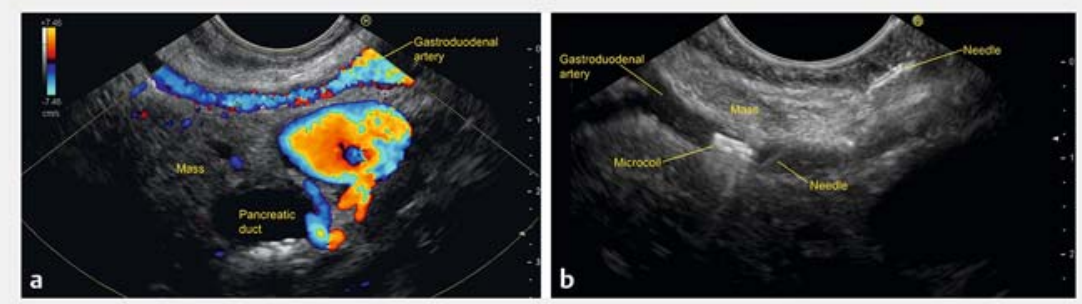

- Fig. 3 Endoscopic ultrasound (EUS)-guided coiling of the gastroduodenal artery (GDA) was performed. a The transducer was first placed parallel to the artery in the antrum so that the diameter of the GDA could be measured to select the appropriate size of microcoil. $\mathbf{b}$ The GDA was punctured with a 22-gauge needle under EUS guidance and two 4-mm microcoils were placed.
Corresponding author

\section{Malay Sharma, MD, DM}

Department of Gastroenterology, Jaswant Rai Speciality Hospital, Saket, Meerut, PIN-250 001, Uttar Pradesh, India

Fax: +91-121-2657154

sharmamalay@hotmail.com

\section{Acknowledgments}

We would like to thank Pran Prakash for assistance with graphic design.

\section{Bibliography}

DOI https://doi.org/10.1055/a-0599-0058

Published online: 9.5.2018

Endoscopy 2018; 50: E192-E193

(c) Georg Thieme Verlag KG

Stuttgart · New York

ISSN 0013-726X

\section{ENDOSCOPY E-VIDEOS \\ https:/|eref.thieme.de/e-videos}

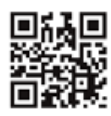

Endoscopy E-Videos is a free access online section, reporting on interesting cases and new techniques in gastroenterological endoscopy. All papers include a high quality video and all contributions are freely accessible online.

This section has its own submission website at https://mc.manuscriptcentral.com/e-videos 